\title{
Radial probe endobronchial ultrasound assisted conventional transbronchial needle aspiration in the diagnosis of solitary peribronchial pulmonary lesion located in the segmental bronchi
}

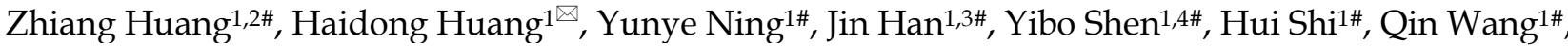 \\ Chong Bai ${ }^{1}$, Qiang Li $^{5}$, Simoff Michael ${ }^{6}$, Paul Zarogoulidis ${ }^{\circledR}$, Wolfgang Hohenforst-Schmidt ${ }^{8}$, Fotis \\ Konstantinou9 9 , J. Francis Turner10, Charilaos Koulouris11, Athanasios Katsaounis'11, Aikaterini Amaniti, \\ Stylianos Mantalovas ${ }^{11}$, Efstathios Pavlidis ${ }^{11}$, Dimitrios Giannakidis ${ }^{11}$, Ioannis Passos ${ }^{11}$, Nikolaos \\ Michalopoulos ${ }^{11}$, Christoforos Kosmidis ${ }^{11}$, Stelian Ştefăniță Mogoantă ${ }^{12}$, Konstantinos Sapalidis ${ }^{11}$ \\ 1. Department of Respiratory \& Critical Care Medicine, Changhai Hospital, the Second Military Medical University, Shanghai, 200433, China \\ 2. Department of Respiratory, The First Affiliated Hospital of Henan University, Henan Kaifeng, 475000, China \\ 3. Department of Respiratory Medicine, The Hospital of Yantaishan, Shandong Yantai, 264000, China \\ 4. Department of Respiratory Medicine, The Fourth People's Hospital of Zigong, Sichuan Zigong, 643000, China \\ 5. The Diagnostic and Therapeutic Center of Respiratory Diseases, Shanghai East Hospital, Tongji University, Shanghai, China \\ 6. Department of Pulmonary and Critical Care Medicine, Henry Ford Hospital, Detroit, Michigan.Detroit,USA \\ 7. Pulmonary Oncology Unit, "G. Papanikolaou” General Hospital, Aristotle University of Thessaloniki, Thessaloniki, Greece \\ 8. Sana Clinic Group Franken, Department of Cardiology / Pulmonology / Intensive Care / Nephrology, "Hof" Clinics, University of Erlangen, Hof, \\ Germany \\ 9. Thoracic Surgery Department, University General Hospital of Alexandroupolis, Democritus University of Thrace, Alexandroupolis, Greece \\ 10. University of Tennessee Graduate School of Medicine, Department of Medicine, Knoxville, TN, USA \\ 11. 3rd Surgery Department, "AHEPA" University Hospital, Aristotle University of Thessaloniki, Thessaloniki, Greece \\ 12. Department of Surgery, Faculty of Dentistry, University of Medicine and Pharmacy of Craiova, Craiova, Romania \\ \# Zhiang Huang, Yunye Ning, Jin Han, Yibo Shen, Hui Shi and Qin Wang contributed equally to this work.
}

$\triangle$ Corresponding authors: Haidong Huang, MD, Department of Respiratory and Critical Care Medicine, Changhai Hospital, the Second Military Medical University, Changhai Road, \#168, Shanghai, 200433, China, E-mail: hhdongbs@126.com. Paul Zarogoulidis MD \& PHD, Pulmonary Oncology Unit, “G. Papanikolaou" General Hospital, Aristotle University of Thessaloniki, Thessaloniki, Greece, E-mail: pzarog@hotmail.com

(c) Ivyspring International Publisher. This is an open access article distributed under the terms of the Creative Commons Attribution (CC BY-NC) license (https://creativecommons.org/licenses/by-nc/4.0/). See http://ivyspring.com/terms for full terms and conditions.

Received: 2018.07.25; Accepted: 2018.10.27; Published: 2019.01.01

\begin{abstract}
Background: The diagnosis of peribronchial pulmonary lesions located in the tertiary bronchi, also known as segmental bronchi, as well as, the 4th order and 5th order segmental bronchi is very difficult. Histopathological specimens cannot be easily obtained by endobronchial biopsies (EBBX) due to the patent but small segmental bronchial lumen. The aim of the present study was to evaluate the diagnostic accuracy and safety of the novel technique with radial probe endobronchial ultrasound (R-EBUS) assisted conventional transbronchial needle aspiration (C-TBNA) in the diagnosis of solitary peribronchial pulmonary lesions located in segmental bronchi from 3th to 5 th order.
\end{abstract}

Methods: From December 2014 to December 2015, 16 patients with solitary peribronchial pulmonary lesions in the segmental bronchi from 3th to 5 th order confirmed by computed tomography (CT) were enrolled. The lesions were located using radial probe endobronchial ultrasound (R-EBUS) to determine the sites of conventional transbronchial needle aspiration (C-TBNA), then, histopathological specimens were obtained using the technique of C-TBNA. The final pathological diagnosis was made based on the findings from the surgical specimens. Statistical analyses were performed for specimen results and complications.

Results: On pathological evaluation, 14 of the 16 specimens were malignant, including 8 adenocarcinomas, 4 squamous cell carcinomas, and 2 small cell carcinomas, while 2 were non-malignant diseases. The diagnostic accuracy rate, sensitivity and missed diagnosis rates were $87.5 \%, 87.5 \%$ and 
$12.5 \%$, respectively. When Combined the results of cytology with histologic samples obtained from C-TBNA the total diagnostic accuracy rate, sensitivity and missed diagnosis rate were $93.75 \%, 93.75 \%$ and $6.25 \%$, respectively. There were 2 cases of bleeding complications $>5 \mathrm{~mL}$ after C-TBNA, and both were resolved with endobronchial management.

Conclusions: The combination of R-EBUS with C-TBNA was advantageous and safe for the diagnosis of solitary peribronchial pulmonary lesions located in the segmental bronchi. However, possible bleeding complications should be anticipated with needle aspiration. Further verification of this combined application should be investigated in larger clinical trials.

Key words: radial probe endobronchial ultrasound, conventional transbronchial needle aspiration, segmental bronchi, pulmonary lesions, bronchoscope, diagnosis

\section{Introduction}

At present the global incidence of lung cancer is increasing with each passing year. Early diagnosis of lung cancer is critical for patients [1]. Clinically, there are instances of undiagnosed small solitary peribronchial pulmonary lesions located in segmental bronchi from 3th to 5th order with the lumen of 2-4 $\mathrm{mm}$ in diameter, because the diagnostic procedures for tissue biopsy are very difficult $[2,3]$. Tissue cannot be easily reached by endobronchial biopsies (EBBX) due to the diameter of the patent bronchial lumen, while the other test of conventional diagnostic bronchoscopic procedures such as lavaging and brushing tend to obtain low positive cytological results. Furthermore, the endobronchial ultrasound guided transbronchial aspiration (EBUS-TBNA) cannot reach the lesions due to the large size of current convex probe of the EBUS bronchoscope with a $6.9 \mathrm{~mm}$ diameter. CT-guided percutaneous biopsies are associated with a higher risk of complications including pneumothorax or hemoptysis given the small lesions' locations often near large blood vessels and the heart $[4,5]$. Therefore, we performed this study to develop a more effective diagnostic method for solitary peribronchial pulmonary lesions located in segmental bronchi. In this study, 16 patients with solitary peribronchial pulmonary lesions located in the segmental bronchi from 3th to 5th order underwent R-EBUS assisted C-TBNA for pathological diagnosis [3]. The lesions were first located using R-EBUS to determine the target sites for puncture and then C-TBNA was performed to obtain cytologic and histologic specimens. A final pathological diagnosis was made based on the findings from the subsequent surgical specimens obtained by thoracic surgery. Finally, statistical analyses were performed for specimen results and complications. This study was conducted to evaluate the diagnostic accuracy and safety of the novel R-EBUS assisted C-TBNA technique in the diagnosis of solitary peribronchial pulmonary lesions located in the segmental bronchi.

\section{Patients and Methods}

\subsection{Patients}

A retrospective analysis of bronchoscopic procedures was performed in the bronchoscopy suite of Changhai hospital between December 2014 and December 2015. During this period, 5085 bronchoscopic procedures were performed, among which 3376 were diagnostic. Out of the 3376 diagnostic bronchoscopies, R-EBUS was used to identify 188 lesions. Thirty of these 188 lesions were located in the segmental bronchi from the 3rd to 5th order. Based on the bronchoscopic findings, 16 out of these 30 lesions were in peribronchial with a patent endobronchial lumen. The distribution of these 16 lesions is shown in Figure 1. Therefore, in the present study these 16 patients ( 13 male and 3 female; mean age, $59.63 \pm 11.10$ years; age range, 33-77 years) underwent R-EBUS assisted C-TBNA for pathological diagnosis.

Inclusion criteria: Solitary peribronchial pulmonary lesions located in the segmental bronchi from 3th to 5th order were confirmed by CT. No mediastinal or hilar lymph node enlargement was found. Endobronchial lumens were patent by the detection of bronchoscopic findings as well as R-EBUS. Exclusion criteria: 1) severe cardiopulmonary dysfunction 2) coagulopathy 3) patients unable to tolerate bronchoscopic procedures. All the patients had signed informed consents, and this study was approved by the ethics committee of Changhai Hospital.

\subsection{Methods}

\subsubsection{Preoperative Preparation:}

The patients were fasted for 8 hours and prohibited from drinking water for 4 hours before the examination. Pulmonary spiral CT scan, blood tests, and ECG were performed as routine examinations. Two bronchoscopists, who were proficient in C-TBNA and endobronchial ultrasound techniques, 
reviewed the chest $\mathrm{CT}$ before procedure to make sure the location of the solitary lesions.

\subsubsection{Operation:}

As shown in Figure 2, the puncture process was divided into three steps: location, measurement and puncture.

The first step was to find the segmental bronchi with peribronchial lesion by R-EBUS, namely location. When operating, the bronchoscopist inserted the bronchoscope into the segmental bronchi closest to the lesion according to the CT scan. Then the R-EBUS probe was inserted into the segmental bronchi by the working channel of bronchoscope, the R-EBUS probe was operated and scanned with a 360-degree ring to obtain the complete ultrasonic image of peribronchial lesion, and all the bronchi in the target area were searched in turn. When the R-EBUS probe got the best ultrasounic image of the peribronchial lesion, the segmental bronchi with peribronchial lesion were recorded remembered.

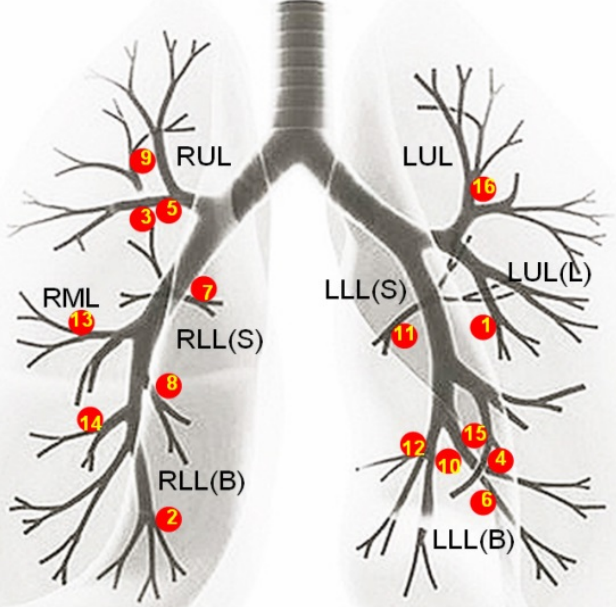

Figure 1. The distribution of all the solitary peribronchial pulmonary lesions. As shown above the distribution of all the 16 solitary peribronchial pulmonary lesions is: 3 lesions were present in the RUL, 1 lesion was in the RML, 1 lesion was in the RLL(S), 3 lesions were in the RLL(B), 1 lesion was in the LUL, 1 lesion was in the LUL(L), 1 lesion was in the LLL(S), and 5 lesions were in the LLL(B). The numbers in the figure followed the sequence of patients' enrollment. (RUL=right upper lobe, $R M L=$ right middle lobe, $R L L(S)$ =superior segment of right low lobe, $R L L(B)=$ basal segment of right low lobe, $L U L=$ left upper lobe, $L U L(L)=$ lingular segment of left upper lobe, $\operatorname{LL}(S)=$ superior segment of left low lobe, $\operatorname{LL}(B)=$ basal segment of left low lobe.)
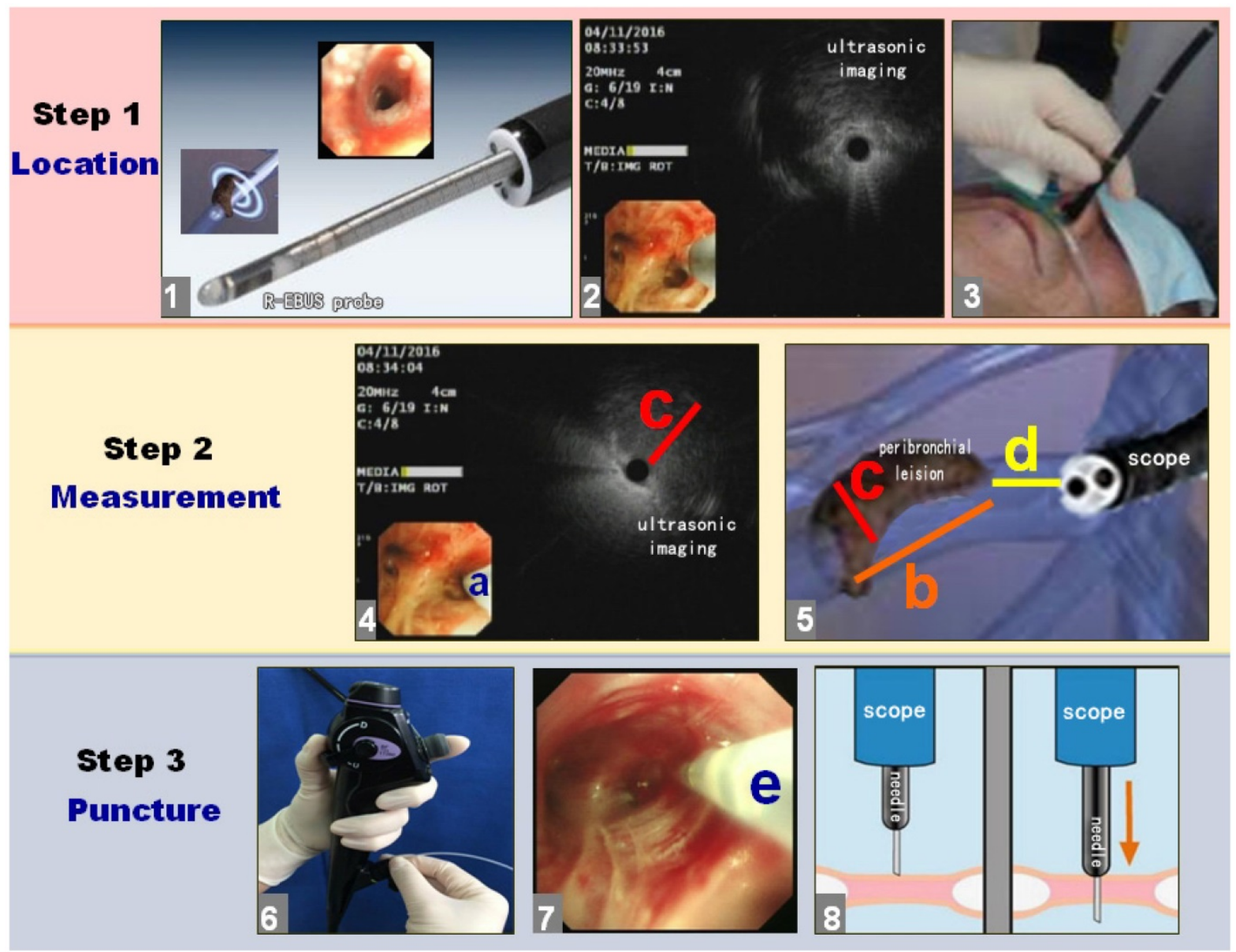

Figure 2. The puncture process with R-EBUS assisted C-TBNA for solitary peribronchial lesion in the segmental bronchi. The puncture process was divided into 3 steps with location, measurement and puncture in sequence, the breakdown of each step was detailed as shown. 
Then, the distal end of bronchoscope was wedged in the nearest segmental bronchus of peribronchial lesion. The assistant was instructed to seize the body of bronchoscope at the level of nose or mouth to ensure bronchoscope not moving. The second step was to measure the size of lesion by R-EBUS, namely measurement. Because the diameter of the bronchial lumen was larger than the R-EBUS probe at the detection site, we used the R-EBUS probe to scan the bronchial wall clockwise until finding the peribronchial lesion. When the ultrasonic probe found the peribronchial lesion, the position and the angle of the ultrasonic probe is the exact endobronchial puncture position and the best puncture angle of the peribronchial lesion (action a). Then, the length (action b) and maximum diameter (action c) of the peribronchial lesion were measured by identifying the proximal, distal, and transverse margins utilizing the ultrasonic image. The R-EBUS probe was then withdrawn to measure the length between the proximal end of the lesion and the distal end of the bronchoscope (action d). The R-EBUS probe was subsequently withdrawn and the 19G WANG TBNA needle was inserted through the working channel of the bronchoscope. The TBNA guide-needle was extended from the distal end of the bronchoscope as determined by action $\mathrm{d}$. The direction as well as the angle of the C-TBNA needle entering the lumen of the segmental bronchi should refer to action a. When the bronchoscopist confirmed that the C-TBNA needle had reached the optimal puncture position and angle, the assistant deployed the 19G WANG TBNA needle core, and the bronchoscopist performed needle aspiration biopsy of the peribronchial lesion by C-TBNA. Since the X-ray fluoroscopy was not used, the "jobbing technique" or "hub against the wall technique" was necessary to be used for bronchoscopist to avoid the failure of C-TBNA caused by the position movement of bronchoscope [6]. The angle of needle biopsy was according to action $b$ and c. During the needle puncture and aspiration, where visual imaging with the bronchoscope was still available in the lumen of segmental bronchial. If the needle could not be penetrated through the bronchial wall, the needlepoint was probablely blocked by the crest of segmental bronchial. The bronchoscopist then readjusted the endobronchial position of C-TBNA needle to puncture again. If necessary, the TBNA needle was withdrawn and the ultrasonic probe reentered to scan the peribronchial lesion and determine the optimal endobronchial puncture site with angle, and then the C-TBNA was redone again. When the puncture needle successfully penetrated through the wall, the assistant then locked the puncture needle, it was connected to a $60 \mathrm{~mL}$ syringe for suction, and the bronchoscopist repeated a rapid jitter or pushed the needle back and forth for several times.

\subsubsection{Specimen Processing:}

The bronchoscopist withdrew the needle with suction off, removed the whole needle assembly from the working channel of the scope and released the specimens from the tip of needle for liquid-based cytology, and histological specimens were removed and fixed in $10 \%$ formalin for histopathology. Some patients underwent endobronchial lavaging and brushing after the puncture, and the specimens were arranged for cytology and the detection of acid-resistant bacilli. Every peribronchial lesion underwent needle puncture 2-3 times.

\subsubsection{Anaesthesia Method:}

All patients were evaluated by an anesthesiologist, and different anesthesia methods including local anesthesia and sedation were selected according to the patients' status and wishes. We initially recommended moderate sedation, which was intravenous anesthesia combined with local anesthesia. Patients received oral nebulization of 10 $\mathrm{mL} 2 \%$ lidocaine injection for oropharyngeal anesthesia, as well as lidocaine gel for nasal anesthesia. Then, the open superficial venous micropump was used to pump an inductive dose of dexmedetomidine at the speed of $1 \mu \mathrm{g} / \mathrm{kg}$. The pump was set up to be emptied in 10-15 min. Then, a maintenance dose was administered at the speed of 0.5-0.7 $\mu \mathrm{g} \mathrm{kg}^{-1} \cdot \mathrm{h}^{-1}$. After the patient fell asleep, a maintainance dose of midazolam $0.03-0.05 \mathrm{mg} / \mathrm{kg}$ and fentanyl 25-50 $\mu \mathrm{g}$ were slowly administered during the procedure. If necessary, the nasopharyngeal airway tube was put to clear the upper respiratory tract. For patients with high risk for sedation such as uncontrolled hypertension and arrhythmia, only local anesthesia by means of oropharyngeal nebulization and nasal anesthesia were used.

\subsubsection{Apparatus:}

All procedures were performed using an electronic flexible bronchoscope (Olympus 1T260 or Olympus 1TQ290, Olympus Medical Systems Co. Ltd, Tokyo, Japan), ultrasonic host (EV-ME1 universal ultrasonic endoscope image processing device, Olympus Medical Systems Co. Ltd., Tokyo, Japan), R-EBUS with a $1.7 \mathrm{~mm}$ diameter (UM-S20-20R, Olympus Medical Systems Co. Ltd., Tokyo, Japan), WANG $^{\text {TM }}$ transbronchial aspiration histology needles (MWF-319, ConMed Company, New York, USA), and a cell brush (Nanjing Micro-tech Medical Science and Technology Co., Ltd., Nanjing, China). 
Table 1. Demographics of patients with solitary peribronchial pulmonary lesions

\begin{tabular}{|c|c|c|c|c|c|c|c|c|}
\hline Case no. & $\begin{array}{l}\text { Age/ } \\
\text { Sex }\end{array}$ & $\begin{array}{l}\text { Peribronchial } \\
\text { Lesion location }\end{array}$ & $\begin{array}{l}\text { Lesion diameter } \\
(\mathrm{mm})\end{array}$ & C-TBNA pathology & $\begin{array}{l}\text { C-TBNA } \\
\text { cytopathology }\end{array}$ & $\begin{array}{l}\text { Airway } \\
\text { washing }\end{array}$ & Airway Brushing & Surgical pathology \\
\hline 1 & $55 / \mathrm{M}$ & LUL.B ${ }^{5}$ & $11 \times 8 \times 9$ & adenocarcinoma & $\begin{array}{l}\text { malignant cell, } \\
\text { suspicious NSCLC }\end{array}$ & negative & negative & $\begin{array}{l}\text { primary } \\
\text { adenocarcinoma }\end{array}$ \\
\hline 2 & $47 / \mathrm{M}$ & RLL.B ${ }^{8}$ & $17.9 \times 15.8 \times 16$ & $\begin{array}{l}\text { suspicious } \\
\text { adenocarcinoma }\end{array}$ & $\begin{array}{l}\text { malignant cell, } \\
\text { suspicious NSCLC }\end{array}$ & negative & $\begin{array}{l}\text { malignant cell, } \\
\text { suspicious NSCLC }\end{array}$ & $\begin{array}{l}\text { primary } \\
\text { adenocarcinoma }\end{array}$ \\
\hline 3 & $45 / \mathrm{M}$ & RUL.B33 & $29.4 \times 27 \times 34.5$ & $\begin{array}{l}\text { suspicious small cell } \\
\text { carcinoma }\end{array}$ & $\begin{array}{l}\text { malignant cell, } \\
\text { suspicious SCLC }\end{array}$ & - & - & small cell carcinoma \\
\hline 4 & $61 / F$ & LLL.B9 & $13.2 \times 15 \times 16.9$ & $\begin{array}{l}\text { suspicious } \\
\text { adenocarcinoma }\end{array}$ & $\begin{array}{l}\text { malignant cell, } \\
\text { suspicious NSCLC }\end{array}$ & negative & - & adenocarcinoma \\
\hline 5 & $63 / \mathrm{M}$ & RUL.B33 & $14.7 \times 13.2 \times 16.5$ & small cell carcinoma & $\begin{array}{l}\text { malignant cell, } \\
\text { suspicious SCLC }\end{array}$ & negative & negative & small cell carcinoma \\
\hline 6 & $63 / \mathrm{M}$ & LLL. ${ }^{9} \mathrm{~b}$ & $10 \times 15.1 \times 13$ & adenocarcinoma & $\begin{array}{l}\text { malignant cell, } \\
\text { suspicious NSCLC }\end{array}$ & negative & negative & $\begin{array}{l}\text { primary } \\
\text { adenocarcinoma }\end{array}$ \\
\hline 7 & $77 / \mathrm{M}$ & RLL.B ${ }^{6}$ & $25.3 \times 23 \times 19$ & $\begin{array}{l}\text { suspicious squamous } \\
\text { cell carcinoma }\end{array}$ & $\begin{array}{l}\text { squamous cell } \\
\text { carcinoma }\end{array}$ & negative & negative & $\begin{array}{l}\text { squamous cell } \\
\text { carcinoma }\end{array}$ \\
\hline 8 & $60 / \mathrm{M}$ & RLL.B ${ }^{7}$ & $15.6 \times 12 \times 13$ & $\begin{array}{l}\text { suspicious } \\
\text { adenocarcinoma }\end{array}$ & $\begin{array}{l}\text { malignant cell, } \\
\text { suspicious NSCLC }\end{array}$ & negative & adenocarcinoma cell & $\begin{array}{l}\text { primary } \\
\text { adenocarcinoma }\end{array}$ \\
\hline 9 & $62 / \mathrm{M}$ & RUL.B²a & $17.5 \times 16.9 \times 15$ & $\begin{array}{l}\text { squamous cell } \\
\text { carcinoma }\end{array}$ & $\begin{array}{l}\text { squamous carcinoma } \\
\text { cell }\end{array}$ & negative & negative & $\begin{array}{l}\text { primary squamous cell } \\
\text { carcinoma }\end{array}$ \\
\hline 10 & $63 / \mathrm{M}$ & LLL.B9 & $14 \times 12 \times 15.5$ & $\begin{array}{l}\text { suspicious } \\
\text { adenocarcinoma }\end{array}$ & $\begin{array}{l}\text { malignant cell, } \\
\text { suspicious NSCLC }\end{array}$ & negative & negative & $\begin{array}{l}\text { primary } \\
\text { adenocarcinoma }\end{array}$ \\
\hline 11 & $75 / \mathrm{M}$ & LLL.B ${ }^{6} \mathrm{C}$ & $30 \times 26 \times 35$ & $\begin{array}{l}\text { suspicious squamous } \\
\text { cell carcinoma }\end{array}$ & negative & negative & $\begin{array}{l}\text { squamous carcinoma } \\
\text { cell }\end{array}$ & $\begin{array}{l}\text { primary squamous cell } \\
\text { carcinoma }\end{array}$ \\
\hline 12 & $54 / \mathrm{M}$ & LLL.B ${ }^{10}$ & $21.3 \times 17 \times 15$ & adenocarcinoma & $\begin{array}{l}\text { malignant cell, } \\
\text { suspicious NSCLC }\end{array}$ & - & adenocarcinoma cell & $\begin{array}{l}\text { primary } \\
\text { adenocarcinoma }\end{array}$ \\
\hline 13 & $70 / \mathrm{M}$ & RML.B ${ }^{4}$ & $7 \times 12.8 \times 9$ & $\begin{array}{l}\text { suspicious } \\
\text { adenocarcinoma }\end{array}$ & $\begin{array}{l}\text { malignant cell, } \\
\text { suspicious NSCLC }\end{array}$ & - & - & $\begin{array}{l}\text { primary } \\
\text { adenocarcinoma }\end{array}$ \\
\hline 14 & $33 / F$ & RLL.B ${ }^{9+10}$ & $21.4 \times 17 \times 19$ & $\begin{array}{l}\text { suspicious squamous } \\
\text { carcinoma cell }\end{array}$ & $\begin{array}{l}\text { squamous carcinoma } \\
\text { cell }\end{array}$ & - & - & $\begin{array}{l}\text { primary squamous cell } \\
\text { carcinoma }\end{array}$ \\
\hline 15 & $62 / F$ & LLL.B9 & $16.5 \times 15 \times 21.1$ & non-malignant disease & $\begin{array}{l}\text { malignant cell, } \\
\text { suspicious NSCLC }\end{array}$ & - & - & $\begin{array}{l}\text { primary } \\
\text { adenocarcinoma }\end{array}$ \\
\hline 16 & $64 / \mathrm{M}$ & LUL.B1 & $11 \times 8 \times 9$ & non-malignant disease & negative & - & - & no clinical follow-up \\
\hline
\end{tabular}

$\mathrm{M}=$ male, $\mathrm{F}=$ female, $\mathrm{RUL}=$ right upper lobe, $\mathrm{RML}=$ right middle lobe, $\mathrm{RLL}=$ right low lobe, $\mathrm{LUL}=$ left upper lobe, $\mathrm{B}=$ bronchus, NSCLC=non-small cell lung cancer, $\mathrm{SCLC}=$ small cell lung cancer, $L L L=$ left low lobe, $C-T B N A=$ conventional transbronchial needle aspiration.

\subsection{Statistical analysis}

SPSS version 16.0 (IBM SPSS Statistics, IBM Corporation, Armonk, New York, USA) was adopted to perform the statistical analyses. Quantitative values were expressed as $\bar{x} \pm S D$ and the statistical significance was determined by $t$-test. Numerical values were presented as percentages (\%). $P<0.05$ was considered statistically significant.

\section{Results}

\subsection{Distribution and size of pulmonary lesions}

The patients' demographic characteristics including the pulmonary lesion locations and sizes were shown in Table 1 . The mean diameter of these lesions was $19.28 \pm 7.16 \mathrm{~mm}$.

\subsection{The anesthesia for patients}

In brief, sedation was performed to 11 patients with a mean age of $56.73 \pm 9.40$. Local anesthesia was performed to 5 patients with a mean age of $66.00 \pm$ 12.92. R-EBUS assisted C-TBNA was successfully performed under both anesthesia methods. We analyzed the age of patients with different anesthesia methods and found that there was no statistically significant difference between two groups $(P=0.12)$.

\subsection{Histopathologic and cytologic results of C-TBNA}

C-TBNA was performed for all the 16 patients, and the pathological results were shown in Table 1. C-TBNA histopathological evaluation of the 16 tissue specimens showed that 14 cases were malignant, including 8 adenocarcinomas, 4 squamous cell carcinomas, and 2 small cell carcinomas, and the remaining 2 were non-malignant disease. With respect to cytologic results of C-TBNA, 14 were malignant, and the remaining 2 were non-malignant. Combining both results, 15 were malignant, including 9 adenocarcinomas $(56.25 \%), 4$ squamous cell carcinomas $(25.00 \%)$, and 2 small cell carcinomas $(12.50 \%), 1$ was non-malignant $(6.25 \%)$ and the patient had no clinical follow-up.

\subsection{Accuracy of different procedures}

According to the patients' states after C-TBNA, some of patients underwent endobronchial bronchoscopic washing and brushing for cytological test; lavaging was performed for 10 patients with all negative results. Brushing was performed for 10 patients, malignant cell were found only in 4 out of 10 . However, C-TBNA was performed for all 16 patients, and 15 of these were malignant. Comparing to the result of final surgical pathology, the diagnostic 
accuracy rate, sensitivity and missed diagnosis rate of the cytological results of washing were 0,0 and $100 \%$, respectively. The diagnostic accuracy rate, sensitivity and missed diagnosis rate of the cytological the results of brushing were $40 \%, 40 \%$ and $60 \%$. However, the accuracy rate, sensitivity and missed diagnosis rate of histopathological results of C-TBNA, were $87.5 \%, 87.5 \%$ and $12.5 \%$, respectively. The diagnostic accuracy rate, sensitivity and missed diagnosis rate of C-TBNA cytological results were $87.5 \%, 87.5 \%$ and $12.5 \%$, respectively. Upon combining both results above, the total diagnostic accuracy rate, sensitivity and missed diagnosis rate were $93.75 \%, 93.75 \%$ and $6.25 \%$, respectively (Table 2 ).

Table 2. Analysis of the results of different diagnostic procedures

\begin{tabular}{llll}
\hline Procedure & $\begin{array}{l}\text { Accuracy rate } \\
(\mathbf{\%})\end{array}$ & $\begin{array}{l}\text { Sensitivity } \\
(\mathbf{\%})\end{array}$ & $\begin{array}{l}\text { missed diagnosis } \\
\text { rate } \\
(\mathbf{\%})\end{array}$ \\
\hline $\begin{array}{l}\text { Histopathological results } \\
\text { of C-TBNA (n=16) }\end{array}$ & $87.5 \%$ & $87.5 \%$ & $12.5 \%$ \\
$\begin{array}{l}\text { Cytological results of C-TBNA (n } \\
=16)\end{array}$ & $87.5 \%$ & $87.5 \%$ & $12.5 \%$ \\
$\begin{array}{l}\text { Cytological results of brushing (n } 40 \% \\
=10)\end{array}$ & $40 \%$ & $60 \%$ \\
$\begin{array}{l}\text { Cytological results of washing (n } \\
=10)\end{array}$ & 0 & $100 \%$ \\
\hline
\end{tabular}

\subsection{Complications}

There were no occurrences of pneumothorax, mediastinal emphysema, or mediastinal hemorrhage in any patient. Only 2 patients had complications of $>5 \mathrm{~mL}$ bleeding after needle puncture, but the bleeding was controlled quickly with bronchoscopic management of bronchoscopic wedge technique and endobronchial ice-saline injection.

\section{Typical cases}

A 55-year-old male patient presented with symptoms of hemoptysis for 10 days. CT confirmed a peribronchial lesion with $11 \times 8 \times 9 \mathrm{~mm}$ in size and located in the lingular lobe of Left upper lobe (Figure 3a). Initial bronchoscopic airway exam was normal (Figure $3 \mathbf{b}$ ), and the lumen of segmental bronchi was patent. The endobronchial lavaging and brushing were performed and both cytological results were negative. Then the second diagnostic bronchoscopic procedures with R-EBUS assisted C-TBNA was performed 2 days later. R-EBUS was used to reach a peribronchial lesion in the orifice B5 segment of LUL. The ultrasonic imaging from radial probe showed a peribronchial solid nodule with continuous clear edge, and $11 \mathrm{~mm}$ in the maximum diameter (Figure 3c). After the needle puncture site with angle was confirmed by R-EBUS, the radial probe was pulled out, then the TBNA needle with 19G in size was inserted through the working channel of the bronchoscope. The "jabbing technique" of C-TBNA needle puncture was performed according to the initial evaluation of R-EBUS (Figure 3d). Satisfactory specimens were obtained, and the histopathological results of C-TBNA showed adenocarcinoma (Figure 3e). The non-small cell cancer cells were found in the cytological results of C-TBNA (Figure 3f). The patient underwent thoracic surgery 5 days later. It was confirmed that pathology of the surgical specimen was consistent with the result of C-TBNA. The final diagnosis of low-differentiated primary adenocarcinoma of LUL was confirmed by immunohistochemical result subsequently.

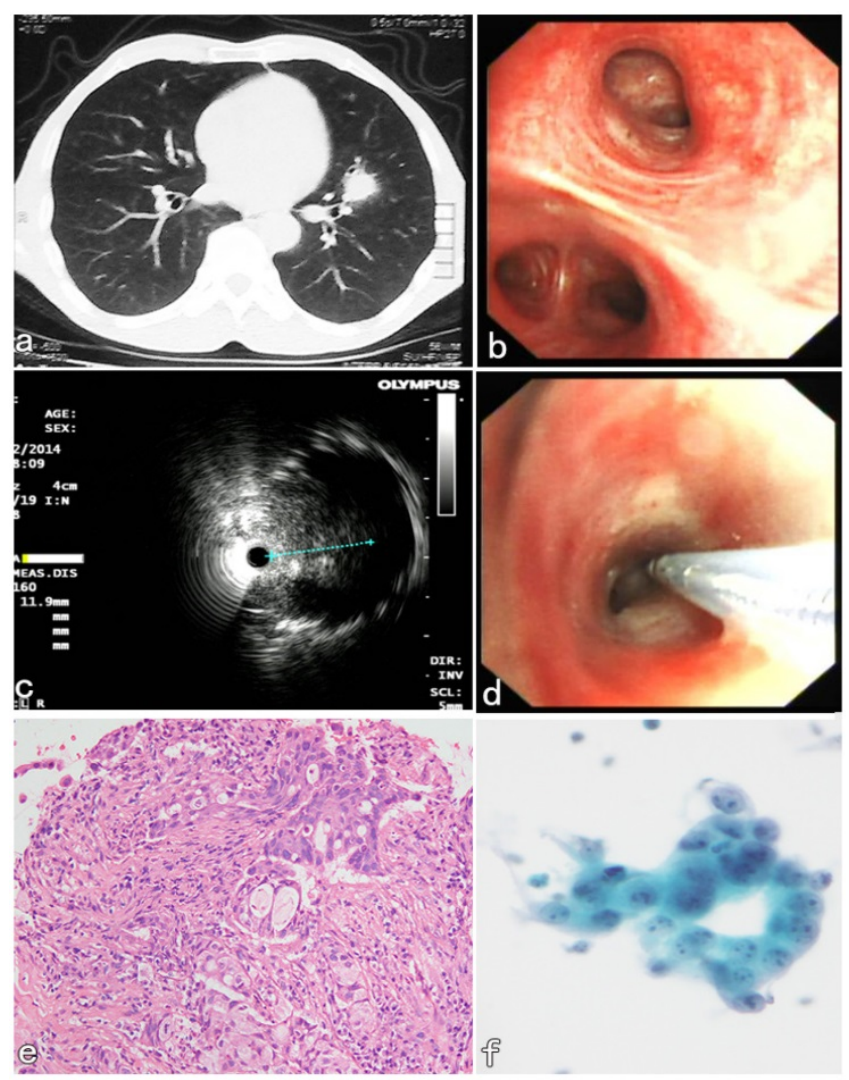

Figure 3. R-EBUS assisted C-TBNA in the diagnosis of a peribronchial pulmonary nodule located in the segmental bronchi of LUL. (a) A solid pulmonary nodule located in the lingular lobe of LUL. (b) Initial bronchoscopic airway exam was normal, the lumen of the segment B5 of LUL was patent. (c) The ultrasonic imaging from radial probe showed a solid peribronchial nodule with continuous clear edge, and $11 \mathrm{~mm}$ in the maximum diameter. (d) The C-TBNA was performed using MW-319 WANG's needle according to the initial evaluation with puncture site and angle obtained by R-EBUS probe. (e) The HE staining of C-TBNA specimen showed typical adenocarcinoma. (f) Malignant cell, suspicious non-small cell lung cancer was found by the cytological result of C-TBNA.

\section{Discussion}

In 1949, Transbronchial needle aspiration, C-TBNA was first proposed by Dr. Eduardo Schieppati in Argentina in diagnosing mediastinal lymph nodes of the central airway by the rigid bronchoscope [7]. Then, in 1978, Ko-Pen Wang in the United States improved the method [8] then C-TBNA 
could be performed by flexible bronchoscope. Wang not only drew the "Wang's TBNA map", systemically described the puncturing methods of mediastinal and hilar lymph nodes [9] and designed a series of C-TBNA needles [10, 11], but also focused on the development and clinical application of C-TBNA puncture techniques. Owing to this, the C-TBNA technique had been the standard method of diagnosis of mediastinal and hilar lymph nodes in the central airway for over 20 years. For an experienced bronchoscopist, the diagnostic yield of mediastinal and hilar lymph nodes by C-TBNA was between $96-100 \%$ [12], while the diagnostic yield of fluoroscopy assisted transbronchial biopsy (TBBX) and C-TBNA could fluctuate between $48 \%$ and $69 \%$ in the diagnosis of pulmonary peripheral lesions (PPLs) [13-15]. C-TBNA became one of the key technologies in diagnostic bronchoscopies. However, with the development of bronchial ultrasonic technologies, especially after 2004, following clinical promotion of a new type of convex probe endotracheal ultrasonic bronchoscope (CP-EBUS), EBUS-TBNA was accepted by clinicians as a safe and efficient technique for mediastinal and hilar lymphadenopathy gradually. At present, the sensitivity and specificity of EBUS-TBNA could reach $89.89 \%$ and $72.73 \%$ respectively in the pathological diagnosis of mediastinal and hilar lymph nodes [16-18]. EBUS-TBNA has expanded the role of C-TBNA in the staging and diagnosis of lung cancer. With the rise of modern navigation technologies, the exploration rate of PPLs can also reach 80-90\% [2]. C-TBNA, therefore, was considered to be an essential technology in both the central airway and in pulmonary peripheral lesions [19].

In the present study, all the 16 peribronchial lesions were located in the segmental bronchi from 3rd to 5th order, where the patent lumen of segmental bronchi was 2-4 mm in diameter. Any technique of endobronchial forceps biopsy, including EBUS-GS was not able to reach the peribronchial lesions, while the EBUS-TBNA scope could not get into the lumen of the fourth bronchus due to the large size of convex probe either. Therefore, C-TBNA has become the only effective diagnostic method to obtain pathological tissue samples. However, there is no "map" available for the peribronchial lesions located in the segmental bronchi, which is different from the fixed distribution of the mediastinal and hilar lymph nodes of the central airway [9], and the endobronchial puncture site of C-TBNA may be very difficult to identify according to the chest CT imaging, even for experienced bronchoscopists. Therefore, we first used R-EBUS to scan the bronchi to find the peribronchial lesion depending on the chest $\mathrm{CT}$ imaging. After the solid peribronchial lesion and the peripheral blood vessels were located, the best angle, location, and depth of the needle puncture were determined by the R-EBUS. Then the C-TBNA procedure using a 19G WANG TBNA needle was performed. As the diameter of proximal endobronchial lumen was more than $4 \mathrm{~mm}$ widely, there was enough space to visually adjust the angle of C-TBNA needle, so that the needle could be advanced to the ideal puncture position with subsequent performance of the conventional method of C-TBNA [6]. The diagnostic yield could be enhanced by the combined techniques with C-TBNA assisted R-EBUS according to our study.

This study also suggested that the current R-EBUS needed to be improved in probing the depth of the peribronchial pulmonary lesions. Further, there was no doppler function equipped with the present ultrasonic radial probe, so it was not effective in distinguishing the peripheral blood vessels closed to the lesion, and this also caused bleeding complications during the needle puncture. In addition, for a peribronchial lesion located in the upper lobe, the C-TBNA procedure using 19G tissue needle combined with a therapeutic bronchoscope sometimes could not be implemented effectively due to limited bending angle of therapeutic bronchoscopic insertion part. Therefore, it is necessary to develop equipment for increasing the diagnostic yield in the future. Fortunately, updated C-TBNA techniques as well as new types of puncture needles for different puncture sites are now available, which have promoted renewal of C-TBNA [20, 21]. In addition, new advanced navigation systems, such as virtual bronchoscopic navigation (VBN) system could be used to evaluate the peribronchial lesions, guide the needle puncture site, angle and depth, as well as reconstruct the large blood vessels around bronchi, and the VBN system offers a more comprehensive and three-dimensional identification, especially in the adjacent relationship between peripheral blood vessels surrounding the lesion as well as the important organs. This helps the C-TBNA to be a safe and efficient method to further improve the diagnostic yield and reduce the complications of bleeding [22-24] (Figure 4).

Similar to our present study, Hanaoka et al. [25] used VBN-assisted C-TBNA in the diagnosis of smaller peribronchial lesions with average size of $11.47 \pm 3.4 \mathrm{~mm}$. C-TBNA was used for obtaining the specimens for all the 15 cases. However, different from our research, C-TBNA needle with $21 \mathrm{G}$ in size was used for the needle aspiration, and the C-TBNA needle was guided to reach the lesion via X-ray fluoroscopy, which could be used to perform the C-TBNA biopsy for smaller lesions located in more 
distal airways. The diagnostic yield could reach $70 \%$ with fewer bleeding complications during the puncture. Both investigations showed the value of C-TBNA technology in diagnosing peribronchial pulmonary lesions located in the segmental bronchi.
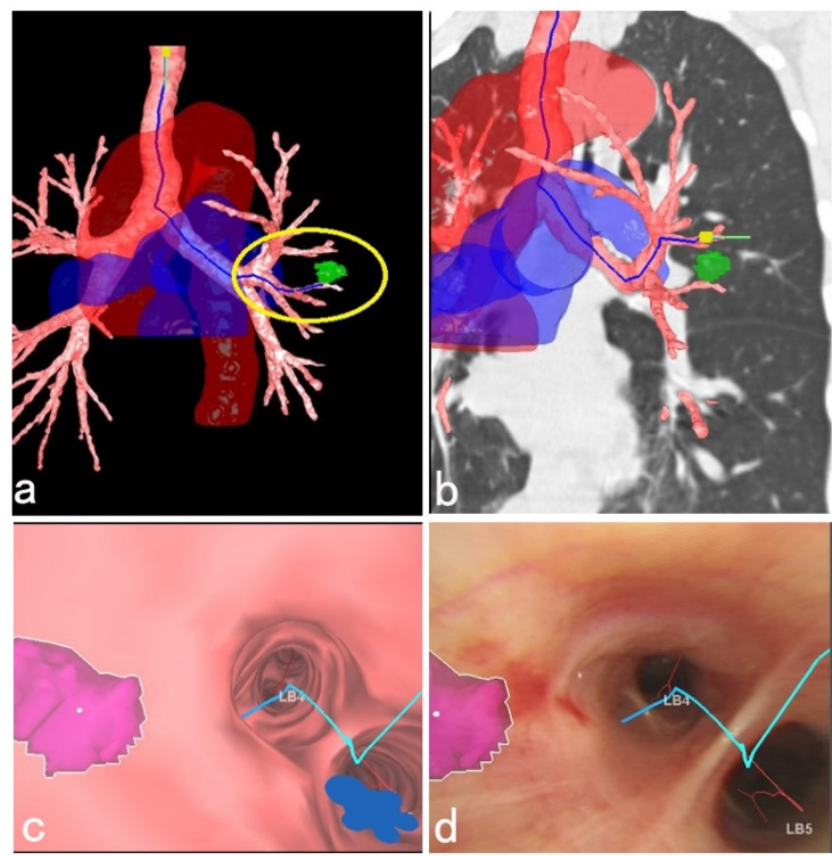

Figure 4. 3D anatomical schematic diagram of a peribronchial pulmonary lesion with surrounding structures reconstructed by the VBN system. (a) $3 D$ anatomical schematic diagram reconstructed by the VBN system showed a peribronchial lesion located in the lingular lobe of left upper lobe, the tracheobronchial tree with surrounding large blood vessels. The green mark within the yellow circle showed the lesion (Lung Point ${ }^{\circ}$ AR Bronchoscopic Navigation, Broncus Medical, Inc.). (b) The lesion could be easily recognized by the fluoroscopy with the help of combination imaging of 3D anatomical schematic diagram and coronary chest CT imaging. (c) The endobronchial location of the solitary peribronchial lesion was seen with the VBN bronchoscopy. (d) During bronchoscopic airway exam, the corresponding position of the peribronchial lesion was marked realtimely to assist the C-TBNA procedure to efficiently obtain the pathological tissue. The final cytological results showed no malignant findings. After 1 year follow-up, the lesion in the left upper lobe shrinked obviously.

Undeniably, there were limitations in the present study. Not all the patients underwent contrast chest $\mathrm{CT}$ scan before the endobronchial procedures, which resulted in the occurrence of bleeding complication in 2 patients. In addition, all procedures were performed by two experienced bronchoscopists. The data is retrospective and limited. Most cases were malignant, and one negative case was not clinically followed up. Therefore, future research on prospective, large-sample data is required.

In recent years, more and more studies have shown the value of C-TBNA in needle aspiration biopsy of the peripheral pulmonary lesions (PPLs) farther from the central airway. Sasada et al. [26] diagnosed PPLs through EBUS-GS-TBNA. A 21G needle was used to obtain specimens through the EBUS-GS. The results showed that there was no statistical difference in the diagnosis yield of the "within" PPLs or "outside" lesions with the guided sheath (GS)-TBNA needle aspiration biopsy [27]. By comparing the diagnostic yield of GS-TBNA, transbronchial catheter aspiration (TBCA) and TBBX in the PPLs, Franke et al. [28] found that GS-TBNA had a higher diagnostic yield for malignant PPLs, and its diagnostic yield was about twice that of TBBX in combination with the result of TBCA. A recent meta-analysis of 18 clinical studies showed that C-TBNA was significantly better than TBBX in the diagnosis of PPLs [29]. The results of AQuIRE of the multi-center prospective study of Ost et al. pointed out that for PPLs, the new navigation technology did not achieve the high diagnostic yield, however, C-TBNA was a key technique to improve the diagnostic yield of PPLs [30-32]. Nevertheless, the application of C-TBNA still faces many challenges in the diagnosis of peribronchial lesions. For example, it is very difficult to adjust the puncture angle of the needle due to the limited diameter of the smaller peripheral airway lumen. In addition, there are no standard methods currently recommended for the procedure of PPLs needle aspiration biopsy. Furthermore, PPLs with ground glass opacity (GGO) in CT imaging may not be easily appreciated by X-ray fluoroscopy and operators still face the problem of excessive radiation exposure when X-ray are used. Fortunately, bronchoscopists' have been able to effectively locate and biopsy the GGO PPLs even with less radiographic exposure with the help of new navigation techniques such as Conebeam CT [33, 34]. Furthermore, new TBNA needle and puncture methods for PPLs are also being developed in recent years [35]. Regarding fine needle biopsy under CT guidance the needle is definitely larger $18 \mathrm{G}$ and higher, however; the complication of pneumothorax is more often. The specimen also is all the time tissue compared to needles of $\leq 25 \mathrm{G}$ which are often used for technical reasons with endoscopic techniques. Several times it is up to the setting of each hospital/institution expertise and equipment to decide for each patient what is the appropriate method of biopsy.

Taken together, C-TBNA still exists as a core diagnostic bronchoscopic technique, which will have great application in prospect. With the development of new technology, use of transbronchial needle aspiration will steadily advance from the central airway to the PPLs to improve the diagnostic yield, simplify the biopsy method, and improve the overall safety of the procedure. Therefore, the fundamental C-TBNA training still needs to be strengthened.

\section{Acknowledgements}

We thank Dr. Ko Pen Wang (Interventional Pulmonology, Division of Pulmonary and Critical Care Medicine, Johns Hopkins University) for 
suggestions and discussions. This study was supported by Translational Medicine of NGS and Precision Medicine in Lung Cancer (2017JZ05), the Projects of Shanghai Zhangjiang National Independent Innovation Demonstration Zone Special Development Fund Major Project (201505-YP-A101002) and Science and Technology Commission of Shanghai Municipality (No.134119a0302).

\section{Competing Interests}

The authors have declared that no competing interest exists.

\section{References}

1. Tsoulos N, Papadopoulou E, Metaxa-Mariatou V, Tsaousis G, Efstathiadou C, Tounta G, et al. Tumor molecular profiling of NSCLC patients using next generation sequencing. Oncology reports. 2017; 38: 3419-29. doi:10.3892/or.2017.6051.

2. Haidong $H$, Yunye N, Wei Z, Zarogoulidis $P$, Hohenforst-Schmidt W, Man $Y G$, et al. Multiple guided technologies based on radial probe endobronchial ultrasound for the diagnosis of solitary peripheral pulmonary lesions: a single-center study. Journal of Cancer. 2017; 8: 3514-21. doi:10.7150/jca.20035.

3. Zaric B, Stojsic V, Carapic V, Kovacevic T, Stojanovic G, Panjkovic M, et al. Radial Endobronchial Ultrasound (EBUS) Guided Suction Catheter-Biopsy in Histological Diagnosis of Peripheral Pulmonary Lesions. Journal of Cancer. 2016; 7: 7-13. doi:10.7150/jca.13081.

4. Boskovic T, Stojanovic M, Stanic J, Pena Karan S, Vujasinovic G, Dragisic D, et al. Pneumothorax after transbronchial needle biopsy. Journal of thoracic disease. 2014; 6: S427-34. doi:10.3978/j.issn.2072-1439.2014.08.37.

5. Boskovic T, Stanic J, Pena-Karan S, Zarogoulidis P, Drevelegas K, Katsikogiannis N, et al. Pneumothorax after transthoracic needle biopsy of lung lesions under CT guidance. Journal of thoracic disease. 2014; 6 Suppl 1: S99-S107. doi:10.3978/j.issn.2072-1439.2013.12.08

6. Liu QH, Ben SQ, Xia Y, Wang KP, Huang HD. Evolution of transbronchial needle aspiration technique. Journal of thoracic disease. 2015; 7: S224-30. doi:10.3978/j.issn.2072-1439.2015.11.31.

7. Schieppati E. [Mediastinal puncture thru the tracheal carina]. Revista de la Asociacion Medica Argentina. 1949; 63: 497-9.

8. Wang KP, Terry P, Marsh B. Bronchoscopic needle aspiration biopsy of paratracheal tumors. The American review of respiratory disease. 1978; 118: 17-21. doi:10.1164/arrd.1978.118.1.17.

9. Wang KP. Staging of bronchogenic carcinoma by bronchoscopy. Chest. 1994; 106: 588-93.

10. Wang KP. Flexible transbronchial needle aspiration biopsy for histologic specimens. Chest. 1985; 88: 860-3.

11. Xia $Y$, Wang KP. Transbronchial needle aspiration: where are we now? Journal of thoracic disease. 2013; 5: 678-82. doi:10.3978/j.issn.2072-1439.2013.09.11.

12. Bonifazi M, Zuccatosta L, Trisolini R, Moja L, Gasparini S. Transbronchial needle aspiration: a systematic review on predictors of a successful aspirate. Respiration; international review of thoracic diseases. 2013; 86: 123-34. doi:10.1159/000350466

13. Wang KP, Haponik EF, Britt EJ, Khouri N, Erozan Y. Transbronchial needle aspiration of peripheral pulmonary nodules. Chest. 1984; 86: 819-23.

14. Shure D, Fedullo PF. Transbronchial needle aspiration of peripheral masses. The American review of respiratory disease. 1983; 128: 1090-2. doi:10.1164/arrd.1983.128.6.1090.

15. Prakash UB, Offord KP, Stubbs SE. Bronchoscopy in North America: the ACCP survey. Chest. 1991; 100: 1668-75.

16. Huang $H$, Huang $Z$, Wang $Q$, Wang $X$, Dong $Y$, Zhang $W$, et al. Effectiveness of the Benign and Malignant Diagnosis of Mediastinal and Hilar Lymph Nodes by Endobronchial Ultrasound Elastography. Journal of Cancer. 2017; 8: 1843-8. doi:10.7150/jca.19819.

17. Gu Y, Shi H, Su C, Chen X, Zhang S, Li W, et al. The role of endobronchial ultrasound elastography in the diagnosis of mediastinal and hilar lymph nodes. Oncotarget. 2017; 8: 89194-202. doi:10.18632/oncotarget.19031.

18. Mehta RM, Singla A, Balaji AL, Krishnamurthy S, Bhat RS, Lokanath C. Conventional Transbronchial Needle Aspiration: The Original Guard Who Still Has a Role in Mediastinal Lymph Node Sampling. Journal of bronchology \& interventional pulmonology. 2017; 24: 290-5. doi:10.1097/LBR.0000000000000410.

19. Panchabhai TS, Mehta AC. Historical perspectives of bronchoscopy. Connecting the dots. Annals of the American Thoracic Society. 2015; 12: 631-41. doi:10.1513/AnnalsATS.201502-089PS

20. Yang $\mathrm{H}$, Zhang Y, Wang KP, Ma Y. Transbronchial needle aspiration: development history, current status and future perspective. Journal of thoracic disease. 2015; 7: S279-86. doi:10.3978/j.issn.2072-1439.2015.11.36.
21. Hsu LH, Liu CC, Ko JS, Feng AC, Chu NM. Comparison of 19-gauge eXcelon and WANG MW-319 transbronchial aspiration needles. Thoracic cancer. 2016; 7: 264-70. doi:10.1111/1759-7714.12301.

22. Wang Memoli JS, Nietert PJ, Silvestri GA. Meta-analysis of guided bronchoscopy for the evaluation of the pulmonary nodule. Chest. 2012; 142: 385-93. doi:10.1378/chest.11-1764.

23. Dolina MY, Cornish DC, Merritt SA, Rai L, Mahraj R, Higgins WE, et al. Interbronchoscopist variability in endobronchial path selection: a simulation study. Chest. 2008; 133: 897-905. doi:10.1378/chest.07-2540.

24. Reynisson PJ, Hofstad EF, Leira HO, Askeland C, Lango T, Sorger $\mathrm{H}$, et al. A new visualization method for navigated bronchoscopy. Minimally invasive therapy \& allied technologies : MITAT : official journal of the Society for Minimally Invasive Therapy. 2018; 27: 119-26. doi:10.1080/ 13645706.2017.1327870.

25. Yasuo M, Kobayashi T, Hama M, Ichiyama T, Horiuchi T, Yamamoto H, et al. Combination of virtual bronchoscopic navigation with conventional transbronchial needle aspiration in the diagnosis of peribronchial pulmonary lesions located in the middle third of the lungs. Respiratory investigation. 2016; 54: 355-63. doi:10.1016/j.resinv.2016.04.003.

26. Sasada S, Izumo T, Chavez C, Tsuchida T. Blizzard Sign as a specific endobronchial ultrasound image for ground glass opacity: A case report. Respiratory medicine case reports. 2014; 12: 19-21. doi:10.1016/ j.rmcr.2013.11.003.

27. Takai M, Izumo T, Chavez C, Tsuchida T, Sasada S. Transbronchial needle aspiration through a guide sheath with endobronchial ultrasonography (GS-TBNA) for peripheral pulmonary lesions. Annals of thoracic and cardiovascular surgery : official journal of the Association of Thoracic and Cardiovascular Surgeons of Asia. 2014; 20: 19-25.

28. Franke KJ, Hein M, Domanski U, Nilius G, Schroeder M, Wohlschlaeger J, et al. Transbronchial Catheter Aspiration and Transbronchial Needle Aspiration in the Diagnostic Workup of Peripheral Lung Lesions. Lung. 2015; 193: 767-72. doi:10.1007/s00408-015-9763-1.

29. Mondoni M, Sotgiu G, Bonifazi M, Dore S, Parazzini EM, Carlucci P, et al. Transbronchial needle aspiration in peripheral pulmonary lesions: a systematic review and meta-analysis. The European respiratory journal. 2016; 48: 196-204. doi:10.1183/13993003.00051-2016.

30. Ost DE, Ernst A, Lei X, Feller-Kopman D, Eapen GA, Kovitz KL, et al. Diagnostic yield of endobronchial ultrasound-guided transbronchial needle aspiration: results of the AQuIRE Bronchoscopy Registry. Chest. 2011; 140: 1557-66. doi:10.1378/chest.10-2914.

31. Ost DE, Ernst A, Lei X, Kovitz KL, Benzaquen S, Diaz-Mendoza J, et al. Diagnostic Yield and Complications of Bronchoscopy for Peripheral Lung Lesions. Results of the AQuIRE Registry. American journal of respiratory and critical care medicine. 2016; 193: 68-77. doi:10.1164/rccm.201507-1332OC.

32. Kupeli E. Conventional transbronchial needle aspiration in community practice. Journal of thoracic disease. 2015; 7: S256-65. doi:10.3978/j.issn.2072-1439.2015.11.54.

33. Hohenforst-Schmidt $W$, Zarogoulidis $P$, Vogl $T$, Turner JF, Browning $R$, Linsmeier B, et al. Cone Beam Computertomography (CBCT) in Interventional Chest Medicine - High Feasibility for Endobronchial Realtime Navigation. Journal of Cancer. 2014; 5: 231-41. doi:10.7150/jca.8834.

34. Hohenforst-Schmidt W, Banckwitz R, Zarogoulidis P, Vogl T, Darwiche K, Goldberg E, et al. Radiation Exposure of Patients by Cone Beam CT during Endobronchial Navigation - A Phantom Study. Journal of Cancer. 2014; 5: 192-202. doi:10.7150/jca. 8395 .

35. Tamiya M, Okamoto N, Sasada S, Shiroyama T, Morishita N, Suzuki H, et al. Diagnostic yield of combined bronchoscopy and endobronchial ultrasonography, under LungPoint guidance for small peripheral pulmonary lesions. Respirology. 2013; 18: 834-9. doi:10.1111/resp.12095. 